\title{
Количественная взаимосвязь между структурой и удерживанием в обращенно-фразовой ВЭЖХ: расширенный инкрементный подход для предсказания удерживания триацилглицеринов
}

\author{
Дейнека В.И., Ань Ван Нгуен, Дейнека Л.А. \\ Белгородский государственный нацииональный исследовательский университет, Белгород
}

Поступила в редакцию 28.01.2019 г.

DOI: https://doi.org/10.17308/sorpchrom.2019.19/745

На основе анализа литературных данных по свойствам привитых обращенных фаз и строения

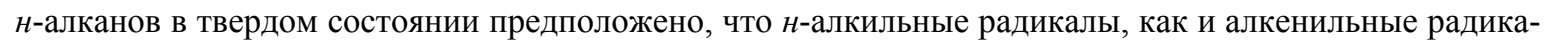
лы с транс $\mathrm{C}=\mathrm{C}$-связями молекул сорбатов могут беспрепятственно внедряться в привитой слой. Однако циис-двойные связи в алкенильном радикале затрудняют этот процесс по стерическим причинам. Это объясняет особенности сорбции сорбатов с н-алкильными и алкенильными радикалами в обращенно-фазовой хроматографии. Показано, что инкрементный подход, основанный на особенностях сорбции радикалов высших жирных кислот и показавший эффективность при анализе удерживания триацилглицеринов, может быть расширен на удерживание веществ с радикалами изомерных (по положению двойной связи в углеродной цепи) радикалов в составе триацилглицеринов жирных кислот. Это положение подтверждено на примере триацилглицеринов, образованных петрозелиновой кислотой (в масле семян моркови), и на масле Limnantes alba, триацилглицерины которого образованы в основном уникальными для растительного мира высшими жирными кислотами.

Ключевые слова: обращенно-фазовая ВЭЖХ, модель строение поверхности, зависимость удерживания триацилглицеринов от их строения, инкрементный подход.

\section{Quantitative relationship between structure and retention in reversed-phase HPLC: an extended incremental approach to predict triacylglycerines retention}

\author{
Deineka V.I., Anh Van Nguyen, Deineka L.A. \\ Belgorod National Research University, Belgorod
}

\begin{abstract}
Based on the analysis of literature data on the properties of grafted reversed phases and the structure of n-alkanes in the solid state, it is assumed that $n$-alkyl substituents of sorbate molecules as well as substituents with trans-alkenyl moieties can easily penetrate the grafted layer. However, the cis-double $\mathrm{C}=\mathrm{C}$-bond in the n-alkenyl substituents the process is hindered for steric reasons, hence the farther from the end of alkenyl substituent is the double bond located the greater is its retention. This explains the features of sorption of sorbates with $n$-alkyl and $n$-alkenyl substituents in reversed-phase chromatography. It is shown that the incremental approach based on the features of the sorption of triacylglycerines with higher fatty acid substituents of different plan seed oils can be extended to the retention of substances with isomeric substituents (by the position of the double bond in the carbon chain) radicals in the composition of triacylglycerols of fatty acids. This was proved by effective prediction of retention of carrot seeds triacylglycerols formed by petroselinic acid (6Z-octadececenoic), as isomers of oleic (9Z-octadececenoic) taking into account the difference of logarithms of retention factor difference for internal and external (relative to the double bond) $\mathrm{CH}_{2}$-group
\end{abstract}


addition. The latter was calculated for a special set of increments for triacylglycerides with substituents of 11Z-eicosenoic and erucic (13Z-docosaenoic) acids vs that for pait of palmitic and stearic acids. The procedure was repeated for unique seed oil Limnantes alba, composed by specific uncommon fatty acid substituents. The procedure was applied to solute retention in reversed-phase HPLC.

Keywords: reversed-phase HPLC, model of surface structure, retention of triacylglycerols, dependence upon structure, incremental approach

\section{Введение}

Обращенно-фазовая высокоэффективная жидкостная хроматография (ОФ ВЭЖХ) относится к числу наиболее часто используемых методов жидкостной хроматографии [1] благодаря широкому диапазону разделяемых соединений по гидрофильности (или гидрофобности). При кажущейся простоте принципов, находящихся в основе разделения, - роста удерживания сорбата с ростом его липофильности [2], существуют необычные явления, которые могут быть объяснены только с учетом зависимости сорбции и от строения сорбата, и от строения сорбента. Так, например, при замене последовательно связанных двух метиленовых групп на двойную $\mathrm{CH}=\mathrm{CH}$-связь изменение удерживания различно в зависимости от строения исходной молекулы. Так, в случае соединений с алкенильными радикалами удерживание уменьшается на величину, превышающую ту, которая возникнет при простом удалении этих двух групп из структуры алкильного радикала [3]. Но для пары «дигидрокверцетин - кверцетин» удерживание, наоборот, замено возрастает [4].

Обычно под обращенно-фазовыми сорбентами понимают силикагели с привитыми алкильными радикалами. При этом такую прививку осуществляют по силанольным группам поверхности силикагеля при действии алкилдиметилхлорсиланов [5]. Многие вопросы по этому процессу рассмотрены в цитируемой монографии, из которой для задач данного исследования важно то, что, в лучшем случае, дериватизации алкилдиметилхлорсиланом подвергается лишь половина поверхностных силанольных групп, концентрация которых изначально составляет немногим менее 5 групп на нм ${ }^{2}$ для полностью гидроксилированной поверхности силикагеля $[5,6]$. Но оценка параметров упаковки $H$-алканов в твердом состоянии [7] показывает возможность замещения всех силанольных групп прямой прививкой алкильных радикалов по гидридной схеме [8].

Настоящая работа посвящена объяснению особенностей разделения триацилглицеринов в условиях ОФ ВЭЖХ в зависимости от их строения и возможности использования инкрементного подхода для предсказания удерживания веществ в рамках количественной взаимосвязи между строением и удерживанием веществ в условиях традиционной обращенно-фазовой хроматографии.

\section{Эксперимент}

Хроматографические исследования были выполнены на хроматографах Shimadzu LC-20 с рефрактометрическим детектором (условия I) и Agilent 1200 Infinity c масс-спектрометрическим детектором (условия II). Хроматографические колонки: 4.6×250 мм Kromasil 100-5C18 (условия I) и $2.1 \times 150$ мм Kromasil 100-3.5C18 (условия II). Подвижные фазы: 100 об. \% ацетон и 10 об. \% ацетонитрила в ацетоне (в условиях ІІ в подвижную фазу добавляли дополнительно $0.01 \mathrm{\Gamma}_{2} \mathrm{дм}^{3}$ формиата аммония). Расход подвижной фазы $0.8 \mathrm{~cm}^{3} /$ мин (условия I) и $0.2 \mathrm{~cm}^{3} /$ мин (условия II). Масс-спектрометрическое детектирование осуществляли в смешанном методе: химическая ионизация при атмосферном давлении (APCI) и ионизация электрораспы- 
лением (ESI), сканировали положительные ионы, образующиеся при ассоциации молекул триацилглицеринов (ТАГ) с ионом аммония $\left[\mathrm{M}+\mathrm{NH}_{4}\right]^{+}$.

Масла были получены экстракцией из семян соответствующих растений, очищенных методом твердофазной экстракции на насадочных картриджах (патронах) ДИАПАК С. Для этого $н$-гексановый экстракт сорбировали на картридже и десорбировали ацетоном.

Триацилглицерины обозначали традиционным методом, в котором перечисляются кислотные остатки в буквенном обозначении без дифференциации позиционных изомеров, которые в условиях обращенно-фазовой хроматографии не разделяются. В работе были использованы буквенные обозначения радикалов жирных кислот: Л - линолевой (9Z,12Z-октадекадиеновой); O - олеиновой (9Z-октадекановой); П - пальмитиновой (гексадекановой); C - стеариновой (октадекановой); A - (11Zэйкозеновой); $A^{*}$ - (5Z-эйкозеновой); Э - эруковой (13Z-додеценовой); Э* - 5Zдодеценовой и Д - 5Z,13Z-додекадиеновой. Символическое обозначение $\mathrm{O}_{2}$ Э указывает на ТАГ, образованной двумя радикалами олеиновой и одним радикалом эруковой кислот.

В инкрементном подходе [9] инкрементами называют разность логарифмов удерживания двух ТАГ, в которых радикал одной кислоты замещен на радикал другой кислоты (например, олеиновой на эруковую, а порядок замены указан стрелочкой):

$$
\Delta(\mathrm{O} \rightarrow \ni)=\operatorname{lgk}\left(\mathrm{O}_{2} Э\right)-\operatorname{lgk}\left(\mathrm{O}_{3}\right)=\operatorname{lgk}\left(\mathrm{O}_{2}\right)-\operatorname{lgk}\left(\mathrm{O}_{2} Э\right)=\ldots
$$

Факторы удерживания рассчитывали по временам удерживания $\left(t_{R}\right)$ ТАГ и «мертвому» времени, $t_{0}$, определенному по удерживанию веществ гомологического ряда [10] - для ТАГ, образованных радикалами миристиновой $(\mathrm{M})$ и пальмитиновой кислот:

$$
\frac{t_{R}\left(\Pi_{3}\right)-t_{0}}{t_{R}\left(M \Pi_{2}\right)-t_{0}}=\frac{t_{R}\left(M \Pi_{2}\right)-t_{0}}{t_{R}\left(M_{2} \Pi\right)-t_{0}}=\frac{t_{R}\left(M_{2} \Pi\right)-t_{0}}{t_{R}\left(M_{3}\right)-t_{0}} .
$$

\section{Обсуждение результатов}

Поскольку плотность привитых алкильных групп на поверхности примерно вдвое ниже чем в твердой фазе $\boldsymbol{H}$-алканов (в направлении, перпендикулярном расположению алкильных радикалов), то $\boldsymbol{H}$-алкильные (и алкенильные с транс $\mathrm{C}=\mathrm{C}$ связью) радикалы сорбатов могут легко проникать внутрь привитой фазы, обеспечивая распределительный механизм [11] удерживания в таком случае, рис.1.

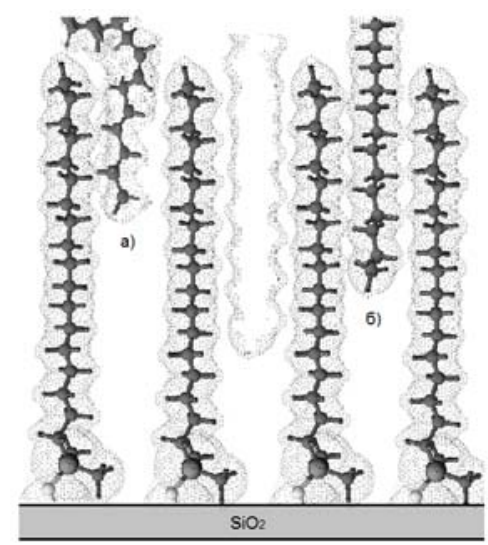

Рис. 1. Модель поверхности силикагеля с привитыми диметилалкилсилильными группами и внедрение в привитой слой цисс-алкенильных (a) и $\boldsymbol{\mu}$-алкильных (б) групп 
Поскольку при циис-конфигурации двойной связи в непредельных кислотах проникновение радикалов в глубину привитой связи затрудняется по стерическим причинам, рис.1, то удерживание непредельных жирных кислот и их производных должно быть тем выше, чем дальше от конца алкенильной части кислотного радикала находится двойная связь. Следовательно, удерживание производных олеиновой кислоты (9-циис-октадеценовой, или $\omega-9$ кислоты) должно быть меньше, чем, например, производных петрозелиновой кислоты (6-циис-октадеценовой, или $\omega-12$ кислоты), или их производных, что реально подтверждается экспериментальными результатами разделения масел с радикалами олеиновой и петрозелиновой кислот, рис.2.

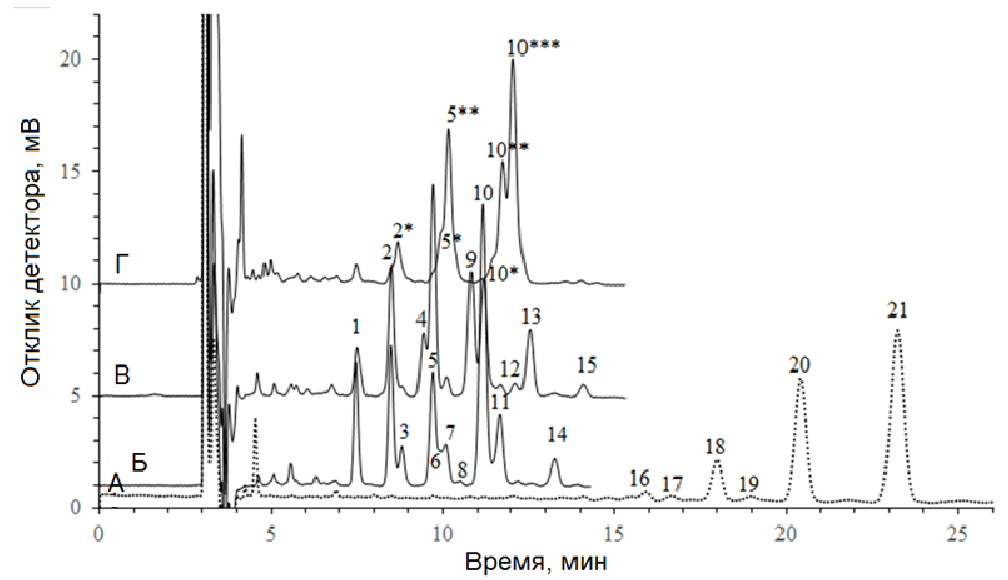

Рис. 2. Разделение триацилглицеринов трех масел сеян: масла: А - семян настурции (Tropaeolum L.), Б - смеси подсолнечного и оливкового, В - дельфиниума,

Г- моркови. Колонка: 4.6×250 мм Kromasil 100-5C18, подвижная фаза: 90 об.\% ацетона и 10 об.\% ацетонитрила, $0.8 \mathrm{~cm}^{3} /$ мин. Температура термостата колонки $30^{\circ} \mathrm{C}$.

Детектирование рефрактометрическое. Отнесение пиков в табл.1-табл.3.

В работе использовали подвижные фазы, составленные из ацетона и ацетонитрила, - наиболее часто используемые в мировой практике и наиболее удобные для ВЭЖХ триацилглицеринов компоненты подвижных фаз благодаря высокой растворимости триацилглицеринов в ацетоне. К тому же эти компоненты обеспечивают относительно высокую разность в коэффициентах преломления между подвижной фазой и анализируемыми веществами, что принципиально важно при использовании рефрактометрического детектирования, не отличающегося высокой чувствительностью. В данных подвижных фазах по мере замены $\mathrm{CH}_{2}-\mathrm{CH}_{2}$-группировки в углеводородных радикалах на $\mathrm{CH}=\mathrm{CH}$-связь удерживание уменьшается вследствие уменьшения липофильности сорбатов (первичный эффект). Предложенная в настоящей работе модель объясняет вторичный эффект, определяющий различие в удерживание соединений с изомерными моноеновыми углеводородными радикалами.

Подвижная фаза 10 об.\% ацетонитрила в ацетоне. Рассмотрим удерживание триацилглицеринов смеси подсолнечного и оливкового масел и масел семян дельфиниума, настурции и моркови, рис.2. Видовой состав триацилглицеринов масел легко определяется по инкрементному подходу и корректность отнесения пиков в настоящей работе была подтверждена параметрами масс-спектров, см. табл. 1 и табл. 2.

По данным, представленным в табл.1, замена олеиновой (О, цис-9октадеценовой) кислоты на цис-11-эйкозеновую (А) кислоту и цис-11-эйкозеновой кислоты на эруковую (Э, цис-13-докозеновую) приводит к одинаковому инкременту:

$$
\Delta \operatorname{in}\left(\mathrm{C}_{2} \mathrm{H}_{4}\right)=\operatorname{lgk}(\mathrm{OA} Э)-\operatorname{lgk}\left(\mathrm{O}_{2} Э\right)=\operatorname{lgk}\left(\mathrm{A}_{2} Э\right)-\operatorname{lgk}(\mathrm{OA} Э)=0.064 \text {. }
$$


Таблица 1. Параметры удерживания масла семян Delphinium grandiflorum и Tropaeolum majus в подвижной фазе 10 об.\% ацетонитрила в ацетоне

\begin{tabular}{|c|c|c|c|c|c|c|c|c|c|}
\hline \multirow{3}{*}{ №1 ${ }^{1}$} & \multirow{3}{*}{$\begin{array}{l}\text { Вид } \\
\text { ТАГ }\end{array}$} & \multirow{3}{*}{$\begin{array}{c}t_{\mathrm{R}}, \\
\text { (мин) }\end{array}$} & \multirow{3}{*}{$\operatorname{lgk}$} & \multirow{2}{*}{\multicolumn{5}{|c|}{ Инкременты, $\Delta(\mathrm{i} \rightarrow \mathrm{j})$, }} & \multirow{3}{*}{$\begin{array}{c}\mathrm{M} / \mathrm{Z} \\
{\left[\mathrm{M}+\mathrm{NH}_{4}\right]^{+}}\end{array}$} \\
\hline & & & & & & & & & \\
\hline & & & & $\pi \rightarrow \mathrm{O}$ & $\mathrm{O} \rightarrow \Pi$ & $\mathrm{O} \rightarrow \mathrm{A}$ & $A \rightarrow \ni$ & $\Pi \rightarrow \mathrm{C}$ & \\
\hline 1 & $\pi_{3}$ & 7.49 & 0.227 & & & & & & 896.8 \\
\hline 2 & $\pi_{2} \mathrm{O}$ & 8.49 & 0.310 & 0.084 & & & & & 898.8 \\
\hline 3 & $\pi_{2} \Pi$ & 8.82 & 0.335 & & 0.024 & & & & 872.7 \\
\hline 4 & $\pi_{2} \mathrm{~A}$ & 9.42 & 0.376 & & & 0.066 & & & 926.8 \\
\hline 5 & $\mathrm{JO}_{2}$ & 9.70 & 0.394 & 0.084 & & & & & 900.8 \\
\hline 6 & $\pi_{2} \mathrm{C}$ & 9.91 & 0.407 & & & & & 0.072 & - \\
\hline 7 & ЛОП & 10.1 & 0.418 & & 0.024 & & & & 874.7 \\
\hline 8 & $\pi \Pi_{2}$ & 10.52 & 0.443 & & 0.024 & & & & - \\
\hline 9 & ЛОА & 10.83 & 0.460 & & & 0.066 & & & 928.8 \\
\hline 10 & $\mathrm{O}_{3}$ & 11.19 & 0.479 & 0.085 & & & & & 902.8 \\
\hline 11 & $\mathrm{O}_{2} \Pi$ & 11.68 & 0.503 & 0.085 & 0.025 & & & & 876.7 \\
\hline 12 & $\pi A_{2}$ & 12.12 & 0.524 & & & 0.064 & & & 956.7 \\
\hline 13 & $\mathrm{O}_{2} \mathrm{~A}$ & 12.54 & 0.544 & & & 0.065 & & & 930.8 \\
\hline 14 & $\mathrm{O}_{2} \mathrm{C}$ & 13.27 & 0.575 & & & & & 0.071 & 904.7 \\
\hline 15 & $\mathrm{OA}_{2}$ & 14.13 & 0.609 & 0.085 & & 0.065 & & & 958.8 \\
\hline \multicolumn{4}{|c|}{ Среднее: } & 0.085 & 0.024 & 0.065 & & 0.072 & \\
\hline 16 & $\mathrm{~A}_{3}+\mathrm{OAЭ}$ & 15.89 & 0.672 & & & 0.063 & 0.063 & & 986.7 \\
\hline 17 & ПАЭ & 16.66 & 0.697 & & 0.025 & & & & 960.7 \\
\hline 18 & $\mathrm{~A}_{2} Э+\mathrm{OЭ}_{2}$ & 18.00 & 0.737 & & 0 & 0.065 & 0.065 & & 1014.8 \\
\hline 19 & $\Pi Э_{2}$ & 18.93 & 0.762 & & 0.025 & & & & 988.6 \\
\hline 20 & $\mathrm{~A}_{2}$ & 20.43 & 0.801 & & & & 0.064 & & 1042.7 \\
\hline 21 & $Э_{3}$ & 23.24 & 0.865 & & & & 0.064 & & 1070.8 \\
\hline \multicolumn{4}{|c|}{ Среднее: } & & 0.025 & 0.064 & 0.064 & & \\
\hline
\end{tabular}

${ }^{1}$ - номера пиков на рис.3.

Таблица 2. Параметры удерживания масла семян моркови в подвижной фазе 10 об.\% ацетонитрила в ацетоне

\begin{tabular}{|c|c|c|c|c|c|}
\hline \multirow{2}{*}{ № ${ }^{1}$} & \multirow{2}{*}{ Вид ТАГ } & \multirow{2}{*}{$t_{\mathrm{R}}$, мин } & \multirow{2}{*}{$\operatorname{lgk}$} & \multicolumn{2}{|c|}{ Инкременты, $\Delta(\mathrm{i} \rightarrow \mathrm{j})$} \\
\hline & & & & $\Omega \rightarrow O$ & $\mathrm{O} \rightarrow \Pi \mathrm{e}$ \\
\hline 1 & $\Omega_{3}$ & 7.49 & 0.227 & & \\
\hline 2 & $\pi_{2} \mathrm{O}$ & 8.49 & 0.310 & 0.084 & \\
\hline $2 *$ & $\Omega_{2} \Pi e$ & 8.69 & 0.325 & & 0.015 \\
\hline 5 & $\mathrm{JO}_{2}$ & 9.70 & 0.394 & 0.084 & \\
\hline $5^{*}$ & ЛОПе & 9.93 & 0.408 & & 0.014 \\
\hline $5 * *$ & $\mathrm{J \Pi е}_{2}$ & 10.16 & 0.422 & & 0.014 \\
\hline 10 & $\mathrm{O}_{3}$ & 11.19 & 0.479 & 0.085 & \\
\hline $10 *$ & $\mathrm{O}_{2} \Pi \mathrm{e}$ & 11.45 & 0.492 & & 0.013 \\
\hline $10 * *$ & $\mathrm{O \Pi e}_{2}$ & 11.75 & 0.509 & & 0.015 \\
\hline $10 * * *$ & $\Pi_{3}$ & 12.06 & 0.522 & & 0.015 \\
\hline \multicolumn{4}{|c|}{ Среднее } & 0.084 & 0.014 \\
\hline
\end{tabular}

\footnotetext{
${ }^{1}$ - номера пиков на рис.3.
}

Этот вклад соответствует введению двух метиленовых групп во внутреннюю часть молекулы кислоты (между карбоксильной группой и двойной связью). Для за- 
мены пальмитиновой кислоты на стеариновую, при котором удлинение цепи проходит условно с внешней стороны, инкремент оказывается несколько больше:

$$
\operatorname{sout}\left(\mathrm{C}_{2} \mathrm{H}_{4}\right)=\operatorname{lgk}\left(\mathrm{C}_{2}\right)-\operatorname{lgk}\left(\Pi Э_{2}\right)=0.073 \text {. }
$$

В таком случае перемещение двух метиленовых групп из внутренней стороны во внешнюю сторону должно сопровождаться ростом удерживания:

$$
\Delta \operatorname{out}\left(\mathrm{C}_{2} \mathrm{H}_{4}\right)-\Delta \operatorname{in}\left(\mathrm{C}_{2} \mathrm{H}_{4}\right)=0.073-0.064=0.009 \text {. }
$$

При переходе от олеиновой (иис-9-октадеценовой) кислоты к петрозелиновой (иис-6-октадеценовой) три метиленовые группы перемещаются с внутренней части молекулы во внешнюю часть. Инкремент на замену олеиновой кислоты на петрозелиновую можно подсчитать по выше найденному инкременту:

$$
\Delta(\mathrm{O} \rightarrow \text { Пе })=0.009 \times 3 / 2=0.0135 .
$$

Это хорошо (в пределах экспериментальной погрешности в определении параметров удерживания веществ с рефрактометрическим детектированием \pm 0.002 ) согласуется с экспериментально найденным значением инкремента (0.014), рассчитанным для масла семян моркови, табл.2.

Подвижная фаза 100 об.\% ацетон. Если инкрементный подход легко применим для масла дельфиниума и настурции, то для еще одного уникального масла, масла семян пенника лугового (Limnanthes alba Bent.), возникают проблемы вследствие уникальности набора жирнокислотных радикалов, не повторяющихся в других маслах. Так, в построении ТАГ вместе с одной относительно обычной эруковой (ее доля в масле около $13 \%$ ) кислотой участвуют и уникальные цис-5-эйкозеновая (А*, основная, - ее доля составляет более $60 \%$ ), иис-5-докозеновая (Э*, с долей около 4\%) и цис,иис-5,13-докозадиеновая (Д, - около 17\%) кислоты [12] при малом числе пиков ТАГ на хроматограмме, рис.3.

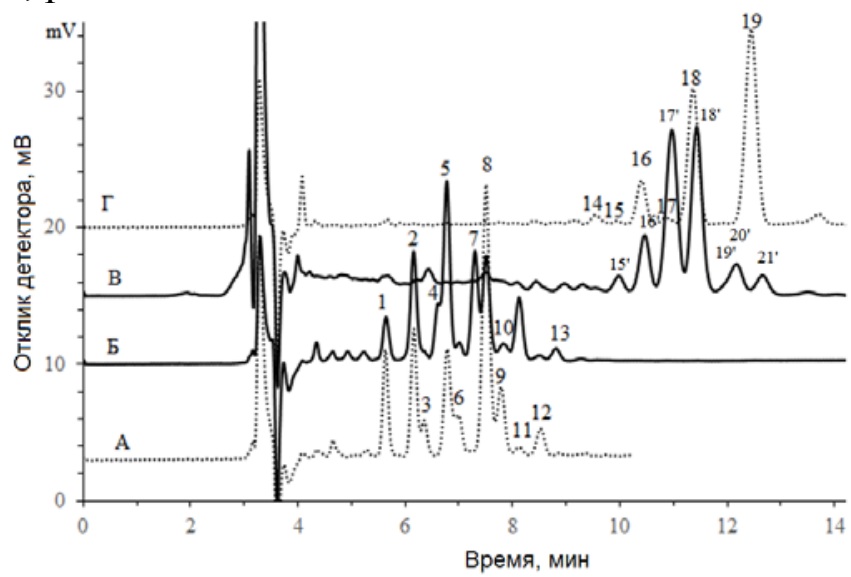

Рис.3. Разделение триацилглицеринов четырех масел семян: Масла семян: А - смеси подсолнечного и оливкового, Б - дельфиниума, В - пенника лугового (Limnanthes alba), Г - настурции. Колонка: 4.6×250 мм Kromasil 100-5С18, подвижная фаза: $100 \%$ ацетона, $0.8 \mathrm{~cm}^{3} /$ мин. Температура термостата колонки $30^{\circ} \mathrm{C}$. Детектирование рефрактометрическое. Отнесение пиков в табл. 3-4.

Но в данном случае можно воспользоваться предложенной выше системой расчетов для предсказания параметров удерживания ТАГ с радикалами указанных кислот.

По табл.3 выполняем расчет

$$
\begin{gathered}
\Delta \operatorname{in}\left(\mathrm{C}_{2} \mathrm{H}_{4}\right)=\operatorname{lgk}(\mathrm{OA} Э)-\operatorname{lgk}\left(\mathrm{O}_{2} Э\right)=\operatorname{lgk}\left(\mathrm{A}_{2} Э\right)-\operatorname{lgk}(\mathrm{OA} Э)=0.052 . \\
\Delta \operatorname{out}\left(\mathrm{C}_{2} \mathrm{H}_{4}\right)=\operatorname{lgk}\left(\mathrm{C}_{2}\right)-\operatorname{lgk}\left(\Pi_{2}\right)=0.061 . \\
\Delta \operatorname{out}\left(\mathrm{C}_{2} \mathrm{H}_{4}\right)-\Delta \operatorname{in}\left(\mathrm{C}_{2} \mathrm{H}_{4}\right)=0.061-0.052=0.009 .
\end{gathered}
$$


Таблица 3. Параметры удерживания масла семян Delphinium grandiflorum и Tropaeolum majus в подвижной фазе $100 \%$ ацетона

\begin{tabular}{|c|c|c|c|c|c|c|c|c|c|}
\hline \multirow{2}{*}{ № ${ }^{1}$} & \multirow{2}{*}{ Вид ТАГ } & \multirow{2}{*}{$t_{\mathrm{R}},($ мин $)$} & \multirow{2}{*}{$\operatorname{lgk}$} & \multicolumn{5}{|c|}{ Инкременты, $\Delta(\mathrm{i} \rightarrow \mathrm{j})$, } & \multirow{2}{*}{$\begin{array}{c}\mathrm{M} / \mathrm{Z} \\
{\left[\mathrm{M}+\mathrm{NH}_{4}\right]^{+}}\end{array}$} \\
\hline & & & & $\pi \rightarrow \mathrm{O}$ & $\mathrm{O} \rightarrow \Pi$ & $\mathrm{O} \rightarrow \mathrm{A}$ & $\mathrm{A} \rightarrow Э$ & $\Pi \rightarrow \mathrm{C}$ & \\
\hline 1 & $\pi_{3}$ & 5.64 & 0.009 & & & & & & 896.8 \\
\hline 2 & $\Omega_{2} \mathrm{O}$ & 6.16 & 0.082 & 0.073 & & & & & 898.8 \\
\hline 3 & $\Omega_{2} \Pi$ & 6.36 & 0.107 & & 0.025 & & & & 872.7 \\
\hline 4 & $\pi_{2} \mathrm{~A}$ & 6.60 & 0.135 & & & 0.053 & & & 926.8 \\
\hline 5 & $\mathrm{JO}_{2}$ & 6.78 & 0.156 & 0.073 & & & & & 900.8 \\
\hline 6 & ЛОП & 7.02 & 0.181 & & 0.025 & & & & 874.7 \\
\hline 7 & ЛОА & 7.29 & 0.208 & & & 0.052 & & & 928.8 \\
\hline 8 & $\mathrm{O}_{3}$ & 7.52 & 0.229 & 0.074 & & & & & 902.8 \\
\hline 9 & $\mathrm{O}_{2} \Pi$ & 7.79 & 0.254 & 0.073 & 0.024 & & & & 876.7 \\
\hline 10 & $\pi A_{2}$ & 7.86 & 0.260 & & & 0.052 & & & 956.7 \\
\hline 11 & $\mathrm{O}_{2} \mathrm{~A}$ & 8.12 & 0.281 & & & 0.052 & & & 930.8 \\
\hline 12 & $\mathrm{O}_{2} \mathrm{C}$ & 8.55 & 0.315 & & & & & 0.061 & 904.7 \\
\hline 13 & $\mathrm{OA}_{2}$ & 8.80 & 0.333 & 0.074 & & 0.052 & & & 958.8 \\
\hline \multicolumn{4}{|c|}{ Среднее: } & 0.073 & 0.025 & 0.052 & & 0.061 & \\
\hline 14 & $\mathrm{~A}_{3}+\mathrm{OAЭ}$ & 9.56 & 0.385 & & & 0.052 & & & 986.7 \\
\hline 15 & ПАЭ & 9.95 & 0.409 & & 0.024 & & & & 960.7 \\
\hline 16 & $\mathrm{~A}_{2} Э+\mathrm{OЭ}_{2}$ & 10.42 & 0.437 & & & & 0.052 & & 1014.8 \\
\hline 17 & $\Pi Э_{2}$ & 10.86 & 0.461 & & 0.024 & & 0.052 & & 988.6 \\
\hline 18 & $\mathrm{~A}_{2}$ & 11.40 & 0.490 & & & & 0.053 & & 1042.7 \\
\hline 19 & $Э_{3}$ & 12.50 & 0.542 & & & & 0.053 & & 1070.8 \\
\hline \multicolumn{4}{|c|}{ Среднее: } & & 0.024 & 0.052 & 0.052 & 0.061 & \\
\hline
\end{tabular}

' номера пиков на рис. 3.

В таком случае для расчета инкремента для замены радикала $\mathrm{A}^{*}$ на радикал Э необходимо удалить из внешней стороны две метиленовые группы и переместить двойную связь на 8 метиленовых групп внутрь молекулы:

$\Delta\left(\mathrm{A}^{*} \rightarrow \ni\right)=\Delta \operatorname{out}\left(\mathrm{C}_{2} \mathrm{H}_{4}\right)-4 \cdot\left(\Delta \operatorname{out}\left(\mathrm{C}_{2} \mathrm{H}_{4}\right)-\Delta \operatorname{in}\left(\mathrm{C}_{2} \mathrm{H}_{4}\right)\right)=0.061-4 \cdot 0.009=0.025$.

Логарифм фактора удерживания триэруката $\left(Э_{3}\right)$ известен из данных для масла семян Tropaeolum majus, и составляет 0.542. Один из основных пиков должен принадлежать ТАГ, содержащему три радикала иис-5-эйкозеновой кислоты $\left(\mathrm{A}^{*}{ }_{3}\right)$. Параметр удерживания такого пика легко рассчитать с учетом трех инкрементов:

$$
\lg k\left(\mathrm{~A}_{3}\right)=\lg k\left(Э_{3}\right)-3 \Delta(\mathrm{A} \rightarrow Э)=0.542-3 \cdot 0.025=0.467 \text {. }
$$

Таблица 4. Параметры удерживания масла семян Limnanthes alba в подвижной фазе $100 \%$ ацетона

\begin{tabular}{|c|c|c|c|c|c|c|c|}
\hline \multirow{2}{*}{ №** } & \multirow{2}{*}{ ТАГ } & \multirow{2}{*}{$t_{R}(\min )$} & \multirow{2}{*}{$\operatorname{lgk}$} & \multicolumn{3}{|c|}{ Инкременты, $\Delta(i \rightarrow j)$} & \multirow{2}{*}{$\begin{array}{c}\mathrm{M} / \mathrm{Z}, \\
{\left[\mathrm{M}+\mathrm{NH}_{4}\right]^{+}}\end{array}$} \\
\hline & & & & $\mathrm{A}^{*} \rightarrow \ni$ & Д $\rightarrow A^{*}$ & $Э \rightarrow{ }^{*}$ & \\
\hline $15^{\prime}$ & $\mathrm{A} * \mathrm{~A} Д+\mathrm{A} * \underline{Z}_{2}$ & 9.98 & 0.411 & & & & $1012+1038$ \\
\hline $16{ }^{\prime}$ & $\mathrm{A} *_{2}$ Д & 10.45 & 0.439 & & 0.028 & & 1012.8 \\
\hline $17^{\prime}$ & $\mathrm{A}_{3}+\mathrm{A}$ *ЭД & 10.92 & 0.465 & 0.026 & 0.026 & & $\underline{986}+1040$ \\
\hline $18^{\prime}$ & $\mathrm{A}^{*}{ }_{2} \ni$ & 11.43 & 0.491 & 0.026 & & & 1014.8 \\
\hline $19^{\prime}$ & $\mathrm{A}^{*} \mathrm{\exists}_{2}$ & 11.95 & 0.516 & 0.025 & & & \multirow{2}{*}{$\underline{1042}+1014$} \\
\hline $20^{\prime}$ & $\mathrm{A} *{ }_{2} \mathrm{~J}^{*}$ & 12.18 & 0.527 & & & 0.036 & \\
\hline $21^{\prime}$ & A*ЭЭ* & 12.71 & 0.551 & & & 0.035 & 1042 \\
\hline
\end{tabular}

\footnotetext{
** номера пиков на рис. 3 .
} 
Такой пик (в пределах экспериментальной погрешности определения логарифма фактора удерживания 0.002) на хроматограмме масле семян пенника лугового имеется (время удерживания 11.92 мин). Более того, такое отнесение пика подтверждается параметрами масс-спектра: в сумме двух ТАГ с близкими временами удерживания имеется пик с $\mathrm{m} / \mathrm{Z}\left(\left[\mathrm{M}\left(\mathrm{A}_{3}\right)_{3}+\mathrm{NH}_{4}\right]^{+}\right)=986$, пик №17' на рис. 3, В. Дальнейшая расшифровка состава ТАГ на этой хроматограмме с учетом найденных инкрементов уже не представляла особой сложности, табл.4, если учесть величину еще одного инкремента:

$$
\Delta\left(Э \rightarrow \Im^{*}\right)=4 \cdot\left(\Delta \operatorname{out}\left(\mathrm{C}_{2} \mathrm{H}_{4}\right)-\Delta \operatorname{in}\left(\mathrm{C}_{2} \mathrm{H}_{4}\right)\right)=4 \cdot 0.009=0.036 .
$$

\section{Заключение}

В работе на основе предложенной модели взаимодействия непредельных жирных кислот с привитым слоем обращенно-фазовых сорбентов объяснены некоторые закономерности удерживания триацилглицеридов. Предложен эффективный метод расчета инкрементов для замен радикалов с заданным изменением их строения, и количественный перенос полученных значений на удерживания других структур с подобными изменениями их структур.

\section{Список литературы}

1. Prathapa B., Dey A., Srinivasa rao G.H., Johnsona P. et al. // Internat. J. Novel Trends Pharm. Sci. 2013. Vol. 3. pp. 15-23.

2. Liu X., Hefesha H., Tanaka H., Scriba G .et al. // Chem. Pharm. Bull. 2008. Vol. 56. pp. 1417-1422.

3. Podlaha O., Töregård B. // J. Chromat. A. 1989. Vol .482. pp. 215-226.

4. Дейнека В.И., Дейнека Л.А., Блинова И.П., Костенко М.О. и др. // Сорбционные и хроматографические проиессы. 2016. Т.16. № 3. С. 377-383.

5. Химия привитых поверхностных соединений. Под. ред. Г.В. Лисичкина. М., ФИЗМАТЛИТ. 2003. 592 с.

\section{References}

1. Prathapa B., Dey A., Srinivasa rao G.H., Johnsona P. et al., Internat. J. Novel Trends Pharm. Sci., 2013, Vol. 3, pp. 15-23. DOI: http://dx.doi.org/10.13040/IJPSR.09758232.3(12).4626-33.

2. Liu X., Hefesha H., Tanaka H., Scriba G., Fahr A., Chem. Pharm. Bull., 2008, 56, 14171422

3. Podlaha O., Töregård B., J. Chromat. A, 1989, Vol. 482, pp. 215-226. https://doi.org/10.1016/S0021-9673(01)93222$\underline{4}$.
6. Zhuravlev L.T. // Langmuir. 1987. Vol. 3. pp. 316-318.

7. Wentzel T., Milner S.T. // J. Chem. Phys. 2010. Vol. 132. 044901.

8. Darmakkolla S.R., Tran H., Gupta A., Rananavare S.B. // RSC $A d v$. 2016. Vol. 6. pp. 93219- 93230.

9. Дейнека В.И., Староверов В.М., Фофанов Г.М., Балятинская Л.Н. // Хим.-фарм. ж. 2002. T. 36. № 7. C. 44-47.

10. Ashes J.R., Mills S.C., Haken J.K. // J. Chromatogr. A. 1978. Vol. 166. pp. 391-396.

11. Дейнека В.И. // Журн. физич. химии. 2008. Т. 82. № 6. С. 1028-1032.

12. Knapp S.J., Crane J.M. // Ind. Crops Prod. 1995. Vol. 4. pp. 219-227.

4. Deineka V.I., Deineka L.A., Blinova I.P., Kostenko M.O., Oleinits E.Y. Sorbtsionnye $i$ khromatograficheskie processy, 2016, Vol. 16, No 3, pp. 377-383.

5. Himiya privityh poverhnostnyh soedinenij, Under red. G.V. Lisichkina. M., Fizmatlit, 2003, $592 \mathrm{p}$.

6. Zhuravlev L.T., Langmuir, 1987, Vol. 3, pp. 316-318. https://doi.org/10.1021/la00075a004.

7. Wentzel T., Milner S.T., J. Chem. Phys. $2010 . \quad$ Vol. 132, 044901. https://doi.org/10.1063/1.3276458. 
8. Darmakkolla S.R., Tran H., Gupta A., Rananavare S.B., $R S C A d v$., 2016, Vol. 6, pp. 9321993230. https://doi.org/10.1039/C6RA20355H.

9. Deineka V.I., Staroverov V.M., Fofanov G.M., Balyatinskaya L.N. Pharm. Chem. J., 2002, Vol. 36, pp. 392-395. https://doi.org/10.1023/A:102100451.

10. Ashes J.R., Mills S.C., Haken J.K., J. Chromatogr. A, 1978, Vol. 166, pp. 391-396.

Дейнека Виктор Иванович - профессор кафедры общей химии, д.х.н., Белгородский государственный национальный исследовательский университет, Белгород

Ань Ван Нгуен - аспирант кафедры общей химии, Белгородский государственный национальный исследовательский университет, Белгород

Дейнека Людмила Александровна - доцент кафедры общей химии, к.х.н., Белгородский государственный национальный исследовательский университет
https://doi.org/10.1016/S0021-9673(00)95621-

8.

11. Deineka V.I., Russ. J. Phys. Chem., 2008, Vol. $\quad 82, \quad$ pp. 902-905. https://doi.org/10.1134/S003602440.

12. Knapp S.J., Crane J.M. Ind. Crops Prod., 1995, Vol. 4, pp. 219-227. https://doi.org/10.1016/0926-6690(95)00035-B

Deineka Victor I. - professor of Common Chemistry Chair of Institute of Engineering Technologies and Natural Sciences of Belgorod State National Research University. Dr. Sci. (Chemistry), e-mail: deineka@,bsu.edu.ru

Anh Van Nguyen - postgraduate of Common Chemistry Chair of Institute of Engineering Technologies and Natural Sciences of Belgorod State National Research University. e-mail: vananhkhoahoasp2@gmail.com

Deineka Ludmila A. - professor assistant of Common Chemistry Chair of Institute of Engineering Technologies and Natural Sciences of Belgorod State National Research University. Ph.D. (Chemistry), e-mail: deyneka@bsu.edu.ru 